\title{
Of FleXibile Manufacturing Systems
}

\author{
BOJAN, I.
}

Abstract: Setting up a flexible manufacturing system (FMS) resembles with the manufacturing assimilation of a new product, particularly of a machine-tool. Consequently, the function of annual expenses for exploiting the machine-tools may be adjusted to calculate the annual expenses of the FMS. In order to determinate the economic flexibility of the FMS, the most important expenses will be exprenssed according to the number of different types of work pieces that must be machined. To determine the flexibility degree of the system for which the expenses are minimal, we compute the values of the function of exploitation expenses in some points corresponding to different types of pieces. The method and the algorithm for the determination of the optimal level of the FMS flexibility are operational because the number of different types of work pieces that must be machined is limited.

Key words: flexibility, exploitation expenses, optimization, FMS
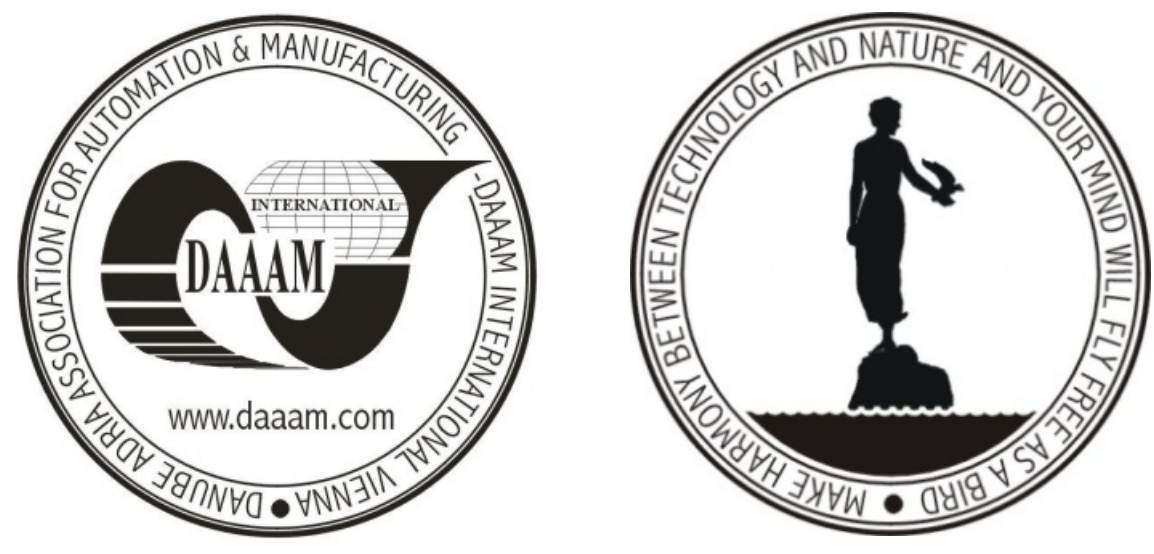

Authors' data: Prof. eng., Ec. Ph.D. Bojan, I[oan]; Department of Management and Systems Engineering, Technical University of Cluj-Napoca, B-dul Muncii 103-105, Romania, prusin@mis.utcluj.ro

This Publication has to be referred as: Bojan, I[oan] (2009). Of Flexible Manufacturing Systems, Chapter 89 in DAAAM International Scientific Book 2009, pp. 915-922, B. Katalinic (Ed.), Published by DAAAM International, ISBN 978-3901509-69-8, ISSN 1726-9687, Vienna, Austria

DOI: $10.2507 /$ daaam.scibook.2009.89 